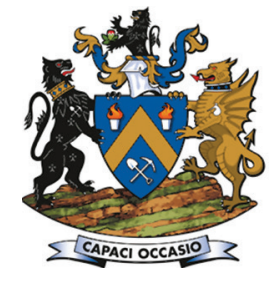

Affiliation:

'Mining Engineering Department, University of Pretoria, South Africa.

Correspondence to:

T. Oates

Email:

thomasxxoates@gmail.com william.spiteri@up.ac.za

\section{Dates:}

Received: 21 Apr. 2021

Revised: 24 Jun. 2021

Accepted: 7 Jul. 2021

Published: August 2021

How to cite:

Oates, T.E. and Spiteri, W. 2021 Stemming and best practice in the mining industry: A literature review.

Journal of the Southern African Institute of Mining and Metallurgy, vol. 121 , no. 8, pp. 415-426

DOI ID:

http://dx.doi.org/10.17159/24119717/1606/2021

ORCID:

T. Oates

https://orcid.org/0000-00019037-0627

\title{
Stemming and best practice in the mining industry: A literature review
}

\author{
T.E. Oates ${ }^{1}$ and W. Spiteri ${ }^{1}$
}

\begin{abstract}
Synopsis
In 2015, after amendments to the explosives regulations, stemming became a mandatory activity for all South African mining operations. There are, however, circumstances in which it is thought stemming has an adverse impact on the blasting outcome. Some of these circumstances include blasting in hot holes, in reactive ground, or when blasting a pre-split. In order to determine when stemming is necessary, its role in the control of adverse blasting phenomena and impact on explosive performance were reviewed. Stemming was found to play a significant role in the fragmentation process and burden movement. Additionally, stemming significantly influences the control of flyrock, air-blast, and toxic fume generation. The review of the literature indicates some motivation for not using stemming for presplit, trim, hot hole, and reactive ground blasting, provided the benefits associated with not stemming the holes outweigh the risks of stemming them. Best practice for stemming from the literature indicates a stemming length of $0.7 \times$ burden is best for larger hole diameters, and 20 to $30 \times \emptyset$ for smaller hole diameters. Crushed aggregate appears to be the most effective stemming material. The South African explosives regulations pertaining to stemming were found to be consistent with those of Australia and the USA.
\end{abstract}

\section{Keywords}

stemming, explosive performance, pre-split, hot hole, reactive ground.

\section{Introduction}

The practice surrounding the use of stemming has in recent years become topical and, in some cases, a controversial subject. Generally, legislation and regulations pertaining to the use of stemming are vague. Literature on stemming and best practices for stemming is also difficult to find. This leaves explosive engineers and blasters on mines divided on what stemming material is best and what quantities of material to use. Additionally, some question the need to use stemming entirely. Particularly for underground mining operations, the use of stemming poses logistical and production challenges. Zhang et al. (2020) state 'Unfortunately, up till now stemming has not been widely used in underground blasts, such as production blasts in underground mining, blasts in tunnelling and drifting, and blasts in other types of underground space construction using explosives'. They attribute this to the lack of quantitative studies demonstrating the necessity and importance of stemming in rock fragmentation.

In 2006 the South African regulations' only requirement for stemming was that underground coal mines use clay, sand, or non-flammable material to stem holes. However, the 2015 amendments essentially required all shot-holes on any surface or underground mine to be stemmed and tamped. Furthermore, the regulations gave guidelines as to the length of stemming required, as well as some forethought regarding the material that should be used. In 2018, more detail was added to the requirements for stemming. The length requirements were replaced by a risk assessment that needs to be conducted with the stemming supplier, explosive supplier, and the competent person conducting the blasting. The risk assessment also needs to include various considerations stipulated in Section 4.14(2) of the GG41904, a Government Gazetted amendment to Chapter 4 of the Mine Health and Safety Act in 2018. Additionally, the stemming material now must comply with the SANS120:2009 code as stipulated in 4.14(3) of the GG41904. The South African regulations stipulate that the purpose of stemming is to reduce the hazards associated with unconfined explosives, blowouts, flyrock, and harmful gases escaping the shot-hole. 


\section{Stemming and best practice in the mining industry: A literature review}

While the requirement to stem holes is apparent to the government, some blasters still question the need to stem blast-holes (Zhang, et al., 2020). This is further complicated by the fact that the use of stemming when performing pre-split blasting or blasting in hot holes is believed to have adverse safety impacts. In the case of pre-split blasting, it is believed that stemming the shot-holes will result in overbreak into the final pit walls, potentially affecting highwall stability. When blasting in hot holes or reactive ground it is believed that stemming may promote the premature detonation of the explosive due to heating under confined conditions. In both these situations, failure to use stemming constitutes a contravention of the explosive regulations, which stipulate that all shot-holes be stemmed. Mines are therefore required to apply for exemption from the Inspector of Mines to enable them to omit stemming under these circumstances. However, very little scientific literature in the public domain exists to substantiate an exemption.

This study aimed at investigating the necessity of stemming through a literature review on the effect of stemming on explosive performance, blast safety, and the use of stemming in pre-split, trim, hot holes, and reactive ground.

The study also reviewed best practice for the selection of stemming length and type. A comparison of international explosive regulations pertaining to stemming in comparable countries was done to determine international regulatory practice relating to stemming.

\section{Literature review}

\section{Effect of stemming on explosive performance}

Stemming has a significant effect on explosive performance. Stemming retains useful explosive gas energy that is wasted in the case of unstemmed holes. This affects the explosive utilization and fragmentation results. An improvement in explosive energy utilization would enable the use of smaller quantities of explosives to achieve the same blasting results. Improvements in fragmentation will result in lower downstream handling costs. While these improvements do not directly indicate the need for stemming, they do reduce costs and improve the productivity and profitability of a mining operation.

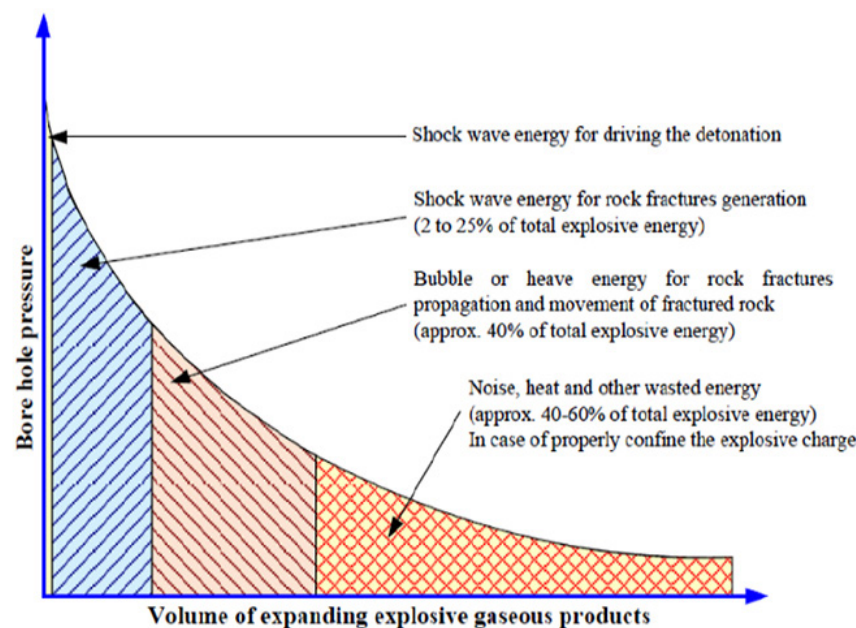

Figure 1-Partition of explosive energy during rock blasting (Sazid, Saharan, and Singh, 2016)

\section{Effect on explosive energy distribution}

When explosives detonate in a shot-hole both shock and gas energy are generated (Tobin, 2013). Generally, the contribution of each of these energies to useful work is as shown in Figure 1. The shock energy is the lesser of the two energies and it drives the detonation process forward in the explosive column as well as generating cracks the surrounding rock mass. The total shock energy component accounts for approximately $2-25 \%$ of the total explosive energy. The useful gas energy accounts for $40 \%$ of the total explosive energy in the case of an adequately confined hole. The gas energy extends the cracks made in the rock mass by the shock energy and heaves the material. The remaining $40-60 \%$ of the total explosive energy manifests as waste energy. (Saharan, Saharan, and Singh, 2016). Dhekne (2015) states that 'the waste energy appears in the form of seismic energy, noise, heat and light'.

The contributions of shock and gas energy differ based on the hardness of the rock. As shown in Figure 2, the gas energy plays a more significant role in soft rock. This is particularly true for lower-order detonations. When a higher-order detonation occurs in hard rock the contributions of shock and gas energy to fracturing the rock are more evenly distributed.

The significance of gas energy in the fragmentation process was highlighted by Mchugh (1981) in a series of tests conducted on lined and unlined explosive charges in a plexiglass cylinder. It was concluded that the gas energy increases the length of the cracks generated by the shock energy by a factor of five to ten. Similarly, Dally et al. (1975) found that 'containing the charge produced cracks which were larger by a factor of seven than those produced with the vented charge'. Sharama and Rai (2015) state that 'the blasthole pressure plays over $80 \%$ of role in fragmenting the rock mass'. Armstrong (1994) states that 'approximately 80 percent of the explosive energy is manifested as gas energy to perform the final fragmentation and movement of the burden material'. This process is driven by the gas energy penetrating fractures generated by the shock energy and lengthening them (McHugh, 1983). Zang (2016) found that stemming seems to affect the size and duration of the dilational wave that fractures the rock mass. Zhang (2016) performed two experiments, one with a vented charge (no stemming) and another with a contained charge (with stemming). It was found that the P-wave leading the compression pulse was 20\% longer and the tailing tension pulse was $50 \%$ higher for the stemmed charge. Additionally, the duration of the tailing pulse was increased by $30 \%$. Zhang (2016) also found that stemming improved the maximum crack radius at crack arrest by a factor of five in comparison to an unstemmed charge. It is thought that each millisecond of increased retention time will increase the work done on the rock mass and reduce waste energy (Eloranta, 1994).

Considering the significance of the gas energy's contribution to successful rock breaking, it is logical to confine this energy in the shot-hole. However, there is a belief, recorded as early as 1912 among miners, that higher velocity of detonation (VOD) explosives do not require stemming as it is thought that the shock energy will break the ground, rather than the gas energy (Snelling and Hall, 1912; Saffy, 1961). This is held to be particularly true by underground miners (Zhang, 2016). However, the literature indicates that explosives with a higher VOD exhibit the greatest improvement in efficiency with the addition of stemming material (Snelling and Hall, 1912). 


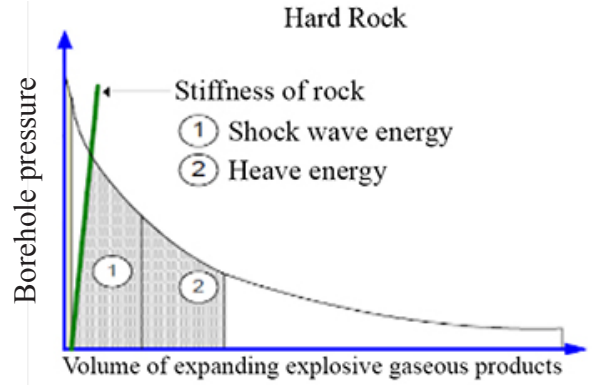

(a) High order detonation

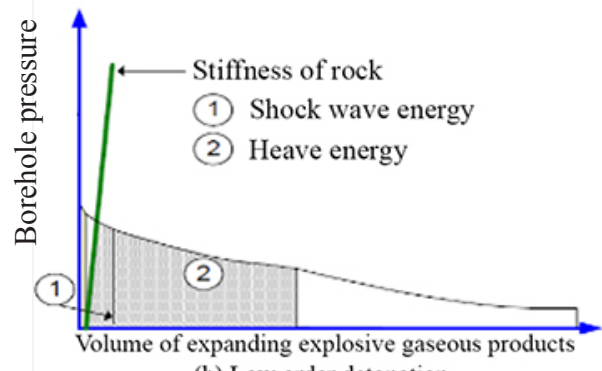

(b) Low order detonation

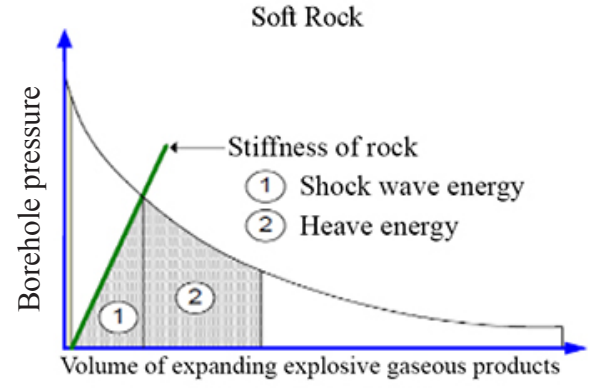

(a) High order detonation

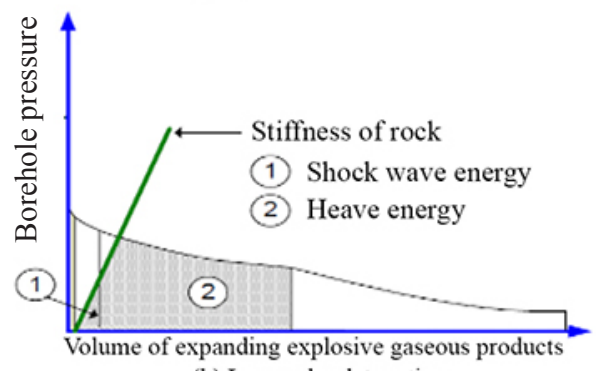

(b) Low order detonation

Figure 2-Schematic energy utilization (Sazid, 2014) after (Brinkmann, 1990; Lownds and Du Plessis 1983)

Explosives with a higher VOD generate significantly greater borehole pressures and, in the absence of stemming, the reaction gases would be rapidly ejected (Pearton, 2014). Snelling and Hall (1912) confirmed this in a series of Trauzl lead-block tests, and found that even a small quantity of stemming significantly improved the efficiency of fast-acting explosives.

Brinkman (1994) found that up to $50 \%$ of the explosive energy (released in the blast-hole) was carried away by gases venting from the collar when no stemming material was used. Brinkman (1994) further found that the use of a single clay tamping plug reduced the energy vented from the blast-hole to as little as $15 \%$ of that of an unconfined hole. Snelling and Hall (1912) found that the use of even the least efficient stemming materials may increase the useful energy of a shot by $60 \%$, and by up to $93 \%$ for the most efficient stemming materials. Konya and Konya (2018) state that proper stemming has been shown to improve explosive efficiency by over $41 \%$.

Based on the available literature it is evident that stemming has a significant impact on the utilization of the explosive energy in a shot-hole. Additionally, the literature indicates the importance of gas energy in the fragmentation process. The view that stemming is unnecessary because the shock energy will fragment the rock is not erroneous. However, the use of a small amount of stemming will significantly improve the rock-breaking efficiency of explosives in a shot-hole (Armstrong, 1994).

\section{Effect on fragmentation.}

Fragmentation is the fundamental goal of explosive rockbreaking. Good fragmentation results in significant benefits down the value chain, particularly in the loading and hauling operations and the crushing circuit of a mining operation (Phamotse and Nhleko, 2019). The use of chemical energy, in the form of explosives instead of mechanical energy to break the rock is widely accepted as cheaper and more efficient.

Stemming plays a significant role in the fragmentation process, improving the total amount of useful explosive energy as well as the distribution of that energy in the blast-hole. Literature on the impact of stemming on fragmentation deals with two issues - the stemming length and the stemming material. Both factors have a significant impact on downstream processes.

When no stemming is used there is a significant impact on the fragmentation. Armstrong (1994) found that a stemmed hole decreases the $K_{50}$, the quadratic mesh size that $50 \%$ of the material of a certain dimension will pass, by $50 \%$ in comparison to an unstemmed hole. Additionally, it was found that the burden velocity increased by $25 \%$ for stemmed holes in comparison to unstemmed holes (Armstrong, 1994).

Zhang et al. (2020) conducted a series of tests using molecular RDX explosives, an energetic and brisant military high explosive, on granite blocks using various stemming materials. From the study, it was concluded that stemmed blasts yield much better fragmentation than unstemmed holes. Zhang et al. (2020) state 'stemmed blasts produce higher mass percentile than unstemmed ones at a given particle size'. They conclude that 'Stemming must be used in all blasts aimed at good rock fragmentation'. Without more quantitative studies to benchmark unstemmed holes against stemmed holes, only the benefits derived from good stemming practices can be used to motivate the necessity of stemming shot-holes.

\section{Effect of stemming length on fragmentation}

There is no generic stemming length rule or ratio that offers the optimum fragmentation. There are guidelines for making initial estimates of the blasting parameter, but the best stemming length is found through trial-and-error iterations.

When the stemming length is too short the holes tend to crater, resulting in the premature venting of explosive energy and reduced fragmentation efficiency along the entire shot-hole. When the stemming is too long it leads to improved gas retention and finer fragmentation in the bottom and middle part of the hole. However, the increased length of stemming reduces the energy in the top of the hole, leading to coarser fragmentation on the top layer of the muckpile (Lachamp, Grannas, and Chavez, 2020).

Trivedi, Singh, and Gupta (2015) mention that the stemming to burden ratio becomes more relevant when blasting hard rock 


\section{Stemming and best practice in the mining industry: A literature review}

near the collar zone. They also noted that rock with natural fractures in the burden region should be stemmed with longer stemming. Lamchap, Grannas, and Chavez (2020) conducted a series of tests based on this idea at a gold mine in northern Sweden, in which stemming lengths were adjusted based on the fractured rock in the collar region of the drill-hole. Stemming lenghts between 2.5 and $3 \mathrm{~m}$ were used, depending on the penetration rate of the drills. Longer stemming was used when the drill logs indicated fractures in the top of the hole. This was done as less energy is required at the top of the hole if the rock is already fractured. Shorter stemming was used when holes did not show significant fracturing, in order to ensure sufficient energy was available in the collar region to fragment the rock. Lamchap, Grannas, and Chavez (2020) found that varying the stemming lengths resulted in fewer stemming blowouts and smaller horizontal movement, which is desirable when trying to limit dilution. A reduction in stemming blowouts is significant as it is associated with reduced flyrock, improved dilution control, and better fragmentation.

\section{Effect of stemming material on fragmentation}

Whereas the literature on the effect of stemming length on fragmentation is somewhat limited, that on the effect of stemming contrivances and different stemming materials is well documented. The length of stemming that is required is somewhat dependent on the type of material used. The more efficient a stemming material at containing explosive energy, the shorter the stemming length required. Konya and Konya (2018) state 'the use of a proper stemming material can reduce the total amount of stemming needed by over 40\%'. A reduction in stemming length while maintaining the same confining effect allows additional explosives to be used in the hole and significantly improves the fragmentation in the collar (Konya and Konya, 2028). Three types of stemming material are mentioned consistently in stemming literature dealing with fragmentation, namely drill chippings, crushed aggregate, and stemming contrivances. Drill chippings are often the benchmark material as they are widely used due to their availability during the charging operation.

Significant improvements in fragmentation have been observed when crushed aggregate is used to replace drill chippings. Authors generally agree that the use of crushed aggregate in the place of drill chippings results in improved fragmentation (Armstrong, 1994; Kojovic, 2005; Richards, 2013; Sharma and Rai, 2015; Konya and Konya, 2018). Sharma and Rai (2015) found that holes stemmed with drill chippings had $K_{50}$ values higher than those stemmed with crushed aggregate. Where crushed aggregate was used in the place of drill chippings a reduction in the size distribution from $0.58-0.77 \mathrm{~m}$ to $0.45-$ $0.59 \mathrm{~m}$ was achieved. Additionally, the holes stemmed with crushed aggregate had a $21.2 \%$ better muckpile throw, and the productivity of loading and hauling improved by $18 \%$. Kojovic (2005) measured the impact of changing from drill chippings to crushed aggregate stemming at Red Dog mine in Alaska. The blasts stemmed with crushed aggregate significantly improved the uniformity of the ROM (run of mine), with a $36 \%$ reduction in semi-autogenous grinding (SAG) mill feed variability. When the ROM feed to the crushers is more uniform the settings on the crushers can be adjusted to reduce the energy required. With a $3 \%$ increase in $<25 \mathrm{~mm}$ material and $3 \%$ decrease in the $F_{80}$ size, a $5 \%$ reduction in the power input for the mill was recorded.
Additionally, the improved fragmentation as a result of the use of crushed aggregate reduced the wear on the crusher, resulting in a $20 \%$ longer period between crusher relines (Kojovic, 2005).

Investgations in which stemming contrivances have been used also indicate a strong relationship between the stemming material and the resulting fragmentation. The use of stemming contrivances tends to improve the blast fragmentation (Karakus et al., 2003; Correa and Navarrete, 2004; Tobin, 2013; Sazid, 2014; Konya and Konya, 2018). A comprehensive review of commercially available stemming contrivances is beyond the scope of this work and would entail a separate dedicated investigation. Suffice to point out that the devices do, to a lesser or greater extent, improve blasting results. An example of this is the Stemming Plug Augmenting Resistance to Stemming Holes (SPARSH), shown in Figure 3. Sazid (2014) conducted several experiments on four different mines comparing the SPARSH to conventional stemming. The introduction of the SPARSH eliminated the occurrence of boulders at all four mines and reduced the mean fragment size by over $30 \%$. The reduction in boulders was achieved by reducing the length of stemming, as seen in Figure 4. Additionally, a 30\% reduction in explosives was achieved while improving the fragmentation. Two of the four mines showed a 50\% improvement in loading and hauling times.

\section{Effect of stemming on adverse blasting phenomena}

The legislative requirement for stemming is rooted in the control of adverse blasting phenomena, as noted in Section 4.14(1) of GG41904 which stipulates stemming is required 'to reduce the hazards of unconfined explosives, blowouts, flyrocks and harmful explosive gases from escaping the shot hole.' This section of the paper will cover the impact of stemming on the following adverse blasting phenomena:

$$
\begin{aligned}
& >\text { Flyrock } \\
& >\text { Air-blast } \\
& >\text { Blasting fumes } \\
& >\text { Ground vibrations. }
\end{aligned}
$$

\section{Effect of stemming on flyrock}

Flyrock is an undesirable phenomenon that accounts for approximately 40-60\% of opencast blasting accidents (Dhekne, 2015). Flyrock is a result of a mismatch of the explosive energy, confinement, and the geomechanical strength of the rock mass. Flyrock typically originates from the bench top or the vertical highwall face (Bajpayee et al., 2001).

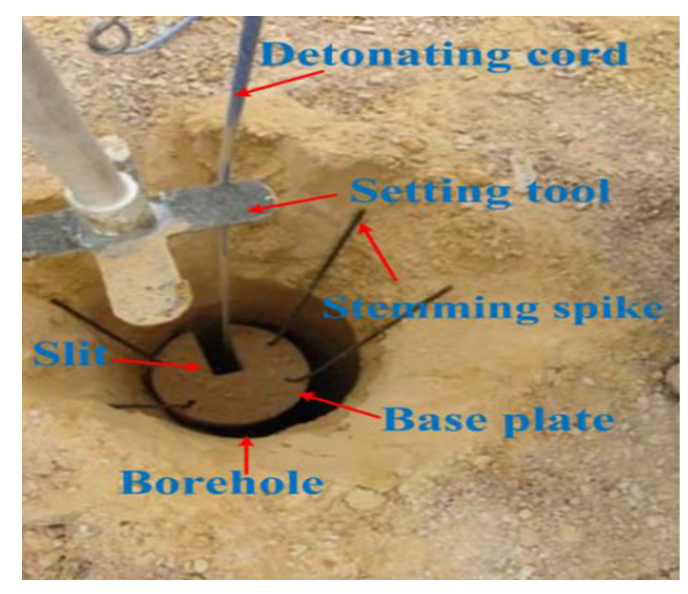

Figure 3-A schematic of a SPARSH (Sazid,2014) 


\section{Stemming and best practice in the mining industry: A literature review}

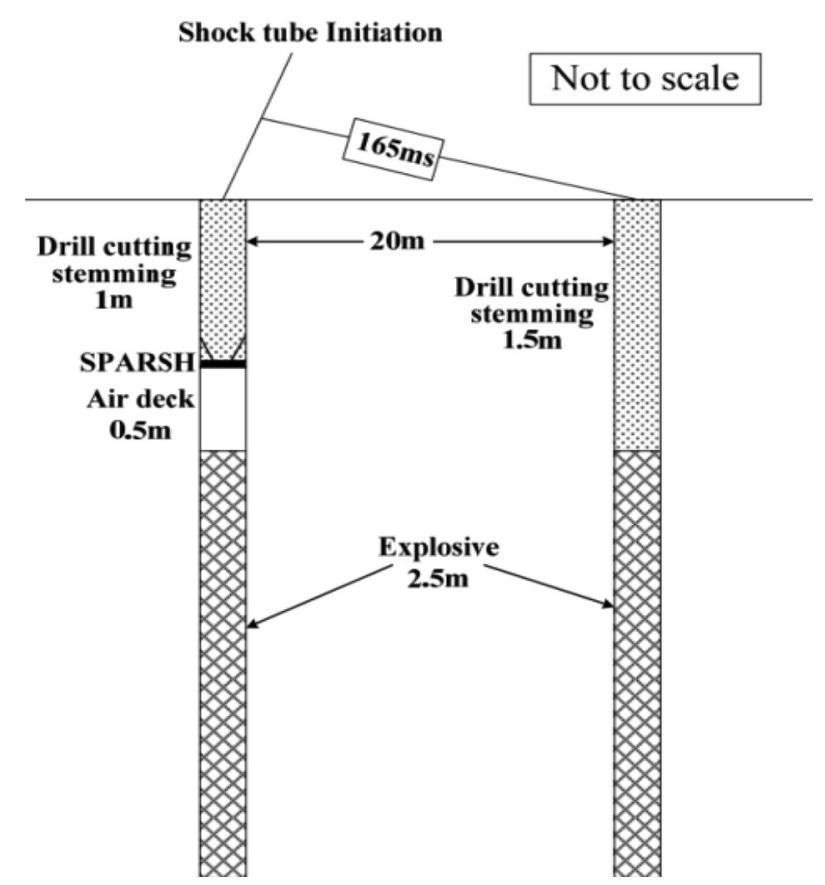

Figure 4-A comparison between the stemming arrangement with SPARSH and conventional stemming (Sazid, 2014)

Flyrock is typically managed by establishment of a blast clearance zone, which is a calculated variable that predicts the maximum travel of flyrock. This clearance zone is calculated using a prediction model such as the Terrock flyrock prediction model.

Flyrock is not well understood. Models are site-specific and non-transferrable (van der Walt and Spiteri, 2020). This is likely why the models at times fail to accurately predict the maximum throw of the flyrock. An event of this nature occurred at a coal mine in Central Queensland where a dwelling $1230 \mathrm{~m}$ from the blast was struck by flyrock with a $1000 \mathrm{~m}$ exclusion zone being set (Downs, 2012). Although the prediction models do mitigate the risk of injury or damage as a result of flyrock, they do not treat the root cause of the flyrock.

\section{Significance of stemming in the control of flyrock.}

While stemming may not be the only factor that contributes to successful flyrock management, it has been identified as a significant control variable. Dhekne (2015) identified stemming material and length as significant influences on the generation of flyrock. Similarly, Ghasemi, Sari, and Ataei (2012) identified stemming, as well as powder factor and burden, as significant control factors of flyrock in an analysis of flyrock prediction models. It can therefore be concluded that stemming (or the lack thereof) plays a causative role in the generation of flyrock (Otuonye, 1981; Armstrong, 1994; Adhikari, 1999; S\&T Projects, 2001; Bajpayee, et al., 2002; Radomsky and kecojevic, 2005; US Department of the Interior, n.d.; Australian Explosives Industry and Safety Group, 2007; Armaghani et al., 2015; Trivedi, Singh, and Gupta, 2015; University of Pretoria, 2016; BME, 2018; Konya and Konya, 2018).

\section{Impact of stemming length on flyrock}

In a study conducted on flyrock at limestone quarries, Adhikari (1999) found that stemming length was one of the most neglected blast design parameters. Stemming length is a significant variable in many flyrock prediction models. The Scale Depth of Burial (SDOB) flyrock prediction model employs an exponential relationship between the stemming length and the calculated clearance distance (ISEE, 2011). However, no model was encountered that included the type of stemming material in flyrock throw prediction. Adhikari (1999) found that the maximum flyrock distance decreases with an increase in stemming length and does not exceed $100 \mathrm{~m}$ when the ratio of stemming length to hole diameter is less than or equal to 20 . It was concluded that flyrock at the limestone quarries would be reduced by ensuring a ratio of stemming length to hole diameter greater than, or equal to 20 , and using a suitable stemming material such as angular gravel (Adhikari, 1999). In a sensitivity analysis by Trivedi, Singh, and Gupta (2015) on an adaptive neuro-fuzzy inference system (ANFIS), the influence of stemming length on the reduction in flyrock distance was found to be more significant for large hole diameters.

\section{Effect of stemming material on flyrock}

There is only limited literature on the influence of the type of stemming material on flyrock. Sharma and Ria (2015) compared the effect of drill chippings to crushed aggregate, and found that flyrock from holes stemmed with crushed aggregate did not leave the bench floor, whereas holes stemmed with drill chippings generated flyrock that reached other benches. The use of stemming plugs in conjunction with stemming materials such as drill chippings is said to reduce stemming ejection, and in turn flyrock (Adhikari, 1999; Karakus et al., 2003; Sazid, 2014).

\section{Effect of stemming on the control of air-blast.}

Air-blast is an inevitable outcome of blasting in the surface mining industry and is typically managed by ensuring that air-blast generated is below a threshold limit. The US Office of Surface Mining and Reclamation Enforcement specifies a safe overpressure level of $133 \mathrm{~dB}$ for impulse air-blast in a frequency range of at least 2--200Hz (Singh, Klemenz, and NiemaanDelius, 2005).

It is well established that stemming is effective at minimizing air-blast in surface blasting activities (Otuonye, 1981; Armstrong, 1994;, Adhikari, 1999; S\&T Projects, 2001; Cunningham et al., 2002, Karakus et al., 2003; Rorke, 2011; Richards, 2013; Bansah et al., 2016; BME, 2018; Konya and Konya, 2018; US Department of the Interior, n.d.). A reduction in air-blast increases the total useful work done by the explosion on the fragmentation and movement (Armstrong, 1994).

\section{Effect of unstemmed holes on air-blast}

Just (1979) reported that unstemmed holes can produce a maximum air blast of $140 \mathrm{~dB}$, while holes stemmed with crushed rock produced $134 \mathrm{~dB}$. Unfortunately, no details of the blasting parameters could be found (Just, 1979). Konya and Konya (2017) state that 'the community impact of proper stemming design is often seen in a reduction of up to $6 \mathrm{~dB}$ of air overpressure', which coincides with the findings of Just (1979). Konya and Konya (2018) similarly mention that air-blast can be reduced by $98 \%$ by the use of adequate stemming. The reduction in air-blast derived by the use of adequate stemming, both in quantity and quality, necessitates the use of stemming in surface blasting.

\section{Effect of stemming on blast-induced vibration}

Ground vibration is an unwanted blasting phenomenon that 


\section{Stemming and best practice in the mining industry: A literature review}

can induce cracking and damage the integrity of structures in the vicinity of the blasting operation (Bansah, et al., 2016). Opinion is divided on the role of stemming in the generation or mitigation of blast-induced ground vibrations. Dhekne (2015) rated stemming length and material as insignificant variables in the reduction of blast-induced ground vibration. Standards Australian (2006) also found stemming quantity and type to be insignificant contributors to ground vibrations. However, some literature indicates a correlation between stemming length and the generation of blast-induced ground vibration. When the stemming is excessive, blast-induced ground vibrations are produced (Sazid, 2014; Konya and Konya, 2018). This is likely the result of the increased SDOB of the explosive charge. Elevli and Arpaz (2010) assessed the relationship of blasting parameters in predictive models and found stemming to account for $13.1 \%$ of the estimated peak particle velocity (PPV). This is likely due to the reduction in powder factor due to the addition of stemming material.

No studies could be found in which the blast-induced ground vibrations were compared for stemmed and unstemmed holes. Therefore, based on the available information, only overstemming holes can be associated with increased blast-induced ground vibrations.

\section{Effect of stemming on the generation of blasting fumes}

Blasting operations produce both toxic and nontoxic gases. The toxic gases are predominately oxides of nitrogen (NOx) and carbon monoxide (CO). The quantity of these gases is a function of the following factors (Maniero, Harris, and Rowland, 2007):

- Formulation of the explosives

- Confinement and age of the explosives

- Contamination of the explosive with water or drill cuttings

$>$ Other.

For this study, the focus was on the confinement of the explosive and the role that it plays in the reduction of toxic explosive-related fumes. Surface mines are typically not as concerned with blasting fumes as underground operations as it is believed that the toxic fumes are dispersed into the open air. However, Maniero, Harris, and Rowland (2007) mention that little work has been done to prove that the orange clouds that are seen after a blast do not contain toxic levels of $\mathrm{NO}_{2}$. Furthermore, they mention that the danger with carbon monoxide is that it remains in the ground after the blast. This occurred in an incident in Kittanning, Pennsylvania, where blast fumes travelled 137 $\mathrm{m}$ from a strip coal mine to a home, poisoning a couple and their baby. The fumes migrate through the ground and collect in confined spaces. Toxic fumes are of greater concern in the underground mining environment as all the air at the working faces needs to be cleared with forced ventilation to decontaminate the air to breathable levels.

In order to minimize the quantity of toxic fumes produced, incomplete detonation needs to be prevented through the use of adequate stemming (Otuonye et al., 1983; US Department of the Interior, n.d.). Additionally, Maniero, Harris, and Rowland (2007) state that 'stemming plugs can be used at the top and bottom of blastholes to prevent the mixture of the blasting agent with drill cuttings or rocks.' Mixing of drill chippings with the blasting agent results in contamination of the explosive, causing increased toxic fume emmissions, reduced explosive performance, and deviation from the designed density of the explosive.

\section{Use of stemming in relation to specialized blasting tech- niques}

Although the effects of stemming are generally beneficial, there are special conditions where additional confinement of the explosive charge is undesirable. The first of these circumstances is where overbreak control is important in blasting techniques such as pre-splitting. The other is when blasting in reactive ground or in hot holes. The additional confinement of the holes is thought to increase the likelihood of a shot-hole detonating instead of deflagrating.

\section{Use of stemming for pre-split blasting}

Tose (2006) states that 'in many circumstances the confined gas energy from explosives can significantly reduce the structural strength of the rock behind and to the sides of the blasted volume'. This is the result of explosive energy creating weaknesses and fractures that reduce the rock mass stability (Tose, 2006). The goal of a pre-split blast is to protect the highwall from explosive-induced fracturing. The addition of stemming improves the rock fracturing action of explosives, thus it would seem intuitive not to stem pre-split blasts. However, firing unstemmed charge-holes is a contravention of the South African explosive regulations. The original legislated requirement for stemming arises from 'to reduce the hazards associated with unconfined explosives, blowouts, fly rocks and harmful explosive gases escaping the shot hole'. All these hazards are still present during a pre-split blast. The decision to stem the holes therefore involves a trade-off between highwall stability and the risks associated with firing unstemmed charges in the case of presplits. Alternatively, new methods of firing pre-split blasts are required to mitigate both risks.

Tose (2006) mentions that pre-split holes should be stemmed if blasting unstemmed holes is likely to cause an annoyance to the neighbours. He further states that stemmed pre-split holes will tend to crater and cause some damage in the crest of the new face. Rorke (2011) recommends the use of a stemming plug, approximately 11 hole diameters in length, at the top of a pre-split hole should excessive air-blast be a concern. The Bulk Mining Explosives (BME) blasting guide stipulates that stemming should not be used in pre-split blasting. However, if necessary, stemming with a length of 10 to 12 hole diameters should be used for noise reduction or rock control (BME, 2018). In an optimization study on the effectiveness of pre-split blasting, Dindarloo (2015) found that leaving pre-split holes unstemmed yielded the best results. While most authors caution against the anticipated air-blast, Rorke (2011) mentions that the factors that cause high air-blast levels are the same as those that create dangerous flyrock and excessive dust. It is reasonable to assume that the firing of unstemmed pre-split holes will be accompanied not only by air-blast but also flyrock and dust.

Not all authors agree with leaving pre-splits unstemmed, though. Konya and Walter (1991) state that 'the upper portion of all pre-split holes, from the top of the charge to the hole collar shall be stemmed'. Bender (n.d.) recommends that the tops of pre-split holes be stemmed, but that a plug should be used to prevent stemming material from packing around the explosive. This is to reduce the coupling ratio of the pre-split charge. Konya and Konya (2018) state that 'stemming is also of extreme importance in overbreak control, with proper stemming leading to a $200 \%$ increase in the performance of pre-split holes versus unstemmed pre-split holes'. Konya and Konya cite personal 


\section{Stemming and best practice in the mining industry: A literature review}

correspondence with Matthews (1978) as the source regarding the $200 \%$ increase in performance; however, the methods used to obtain this data could not be verified, nor the definition of performance concerning pre-split blasting clarified.

Based on the available literature, the consensus appears to be that pre-split blasts should be left unstemmed unless airblast is a concern. However, what is not clear is when air-blast should be a concern. Air-blast accompanied by dust generation and flyrock should not be tolerated. The choice to stem pre-splits will lie in the tolerance for air-blast, flyrock, and dust generation on the mine. The South African Explosive Regulations (2018) stipulate in Section 4.7 that 'the employer at any mine must take reasonable measures to ensure that when blasting takes place, air and ground vibrations, shock waves and fly material are limited to such an extent and at such a distance from any building, public thoroughfare, railway, powerline or any other place where persons congregate to ensure that there is no significant risk to health or safety of persons'.

Therefore, it would be reasonable to assume that should the mine not experience any air-blast, flyrock, shock waves, or ground vibrations that impact the stipulated infrastructure or places of congregation, the pre-splits can be fired without stemming, provided that exemption is granted by the regulatory authority.

Should adverse consequences associated with firing unstemmed charges be an issue, stemming plugs can be used. Konya and Walter (1991) mention that drill chippings are an effective stemming material for pre-splits as the stemming momentarily confines the gases and reduces some of the airblast. Air decking is a controlled blasting technique that has been successfully used in pre-split blasting. An air space is intentionally left above the explosive charge to allow gases generated during detonation to fill the void instead of being forced into the adjacent rock Mass. Eades and Perry (2019) state that 'it is generally accepted that air decking will produce results that are comparable to, but not quite as good as, pre-splitting', particularly for small borehole diameters. Pre-splits can further be improved by decreasing the coupling ratio between the charge and the borehole. The space between the charge and the borehole constitutes an additional void for the charge to dissipate gas energy into before it can permeate the crack network in the surrounding rock mass Eades and Perry (2019). Additionally, the decoupling of the charge results in less localized crushing in the borehole and ultimately less overbreak (Etchells, Sellers, and Furtney, 2013).

Etchells, Sellers, and Furtney (2013) state that overbreak caused by pre-split blasts can be reduced by selecting the correct spacing, decoupling ratio, and split factor. Should a mine require the use of stemming plugs, the efficiency of these can be maximized by using an air deck as well as small-diameter boreholes with the appropriate spacing and a highly decoupled charge with the correct split factor.

Therefore, it is recommended that stemming should be used during pre-splitting to reduce the adverse effects such as flyrock and air-blast associated with firing unstemmed charge holes, unless the mine can present a good case for exemption, e.g. due to the mine's remoteness, where flyrock and air-blast will not influence the areas of concern addressed in the regulations.

\section{Trim blasting}

Trim blasting is another specialized blasting technique in which stemming holes is undesirable. As with pre-split blasting, trim blasting is used to control overbreak by pre-fracturing the rock mass. Trim blasting, in contrast to pre-splitting, involves multiple rows of modified blast-holes instead of the single line used when blasting a pre-split. Owing to the similar mechanisms used in pre-split and trim blasting the same conclusions can be made for trim blasting. Stemming should be used unless the mine can motivate the need for exemption.

\section{Use of stemming in hot hole blasting}

Another circumstance where stemming holes is undesirable is in hot hole blasting. A hot hole, as defined by the South African explosives regulations, is any hole in a coal mine that after being drilled has an in-hole ambient temperature of $40^{\circ} \mathrm{C}$ or an increase of $3^{\circ} \mathrm{C}$ (Department of Mineral Resources, 2018). The use stemming is not desirable on hot holes as confining an explosive that is undergoing heating is more likely to result premature detonation (BHP Billiton, 2008). However, hot holes charged with explosives can detonate with or without stemming In 2006 a shot-hole detonated prematurely during deep hole blasting of pillars on a mechanized coal mine in India. After 2.5 hours a hole charged with a site-mixed system explosive, a cast booster, and a down-the-hole shock tube detonator detonated without stemming. It was later found that the temperature of the strata within a radius of $20 \mathrm{~m}$ from the event was $1010^{\circ} \mathrm{C}$ (Government of India, 2006). In 2003, BHP Billiton experienced an uncontrolled detonation of a shot-hole in hot ground. The shot-hole was charged with heavy ANFO and primed with a $400 \mathrm{~g}$ cast booster and a non-electric detonator used in conjunction with detonating cord. The hole was stemmed with $4 \mathrm{~m}$ of drill chippings, and detonated approximately 15 minutes after the hole showed visible signs of heating (BHP Billiton, 2008). These two incidents indicate that detonation can occur with or without stemming.

While it is commonly thought that not stemming hot holes is beneficial, this is not mentioned specifically in the literature. The South African legislation deals with hot holes only briefly. The regulations stipulate that a written procedure is to be prepared and implemented after consultation with the explosive manufacturer. The procedure must include temperature measurement in the hole by the competent person and recording of the hole temperatures before charging up (DMR, 2018). The guidelines do not mention any specific actions that need to be taken when blasting in hot holes. The literature tends to focus on the following actions when dealing with hot holes (Sharma, 2010):

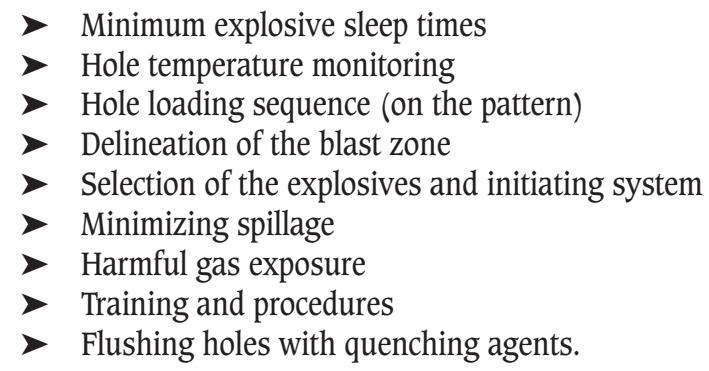

Procedures at mines with hot holes generally stipulate that holes should not be stemmed to avoid a pressure buildup in the hole (BHP Billiton, 2008; Vale, 2019). However, Sharma (2010) states that 'it is good practice sufficient noncombustible stemming material such as sand, crushed stone chips or drill cuttings should be available near the collar of 


\section{Stemming and best practice in the mining industry: A literature review}

each hole prior to commencing the charging operation, in order to fast accomplishing stemming and charging operation'. No other significant literature could be found in the public domain regarding stemming hot holes. Based on the available information it is difficult to conclude as to the necessity of stemming hot holes.

Stemming is necessary to reduce adverse blasting phenomena such as flyrock, air-blast, and toxic fume generation. However, the addition of stemming material may limit visible signs that a hole is undergoing heating and may increase the likelihood of detonation. Further research is needed to clearly identify the role stemming plays in hot hole blasting. Information in this regard will greatly assist mines in motivating for exemption from Section 14.1 of the GG41904 of 2018. If stemming is necessary when blasting in hot holes due to environmental concerns, it should be done as quickly as possible and be the last activity to occur on the bench before blasting to prevent pressure build-up in the hole.

\section{Use of stemming in reactive ground}

Reactive ground is the term applied to a rock type that exothermically reacts with explosives, potentially resulting in premature detonation (Bellairs and Sen, 2004). Reactive ground is not common in South African mines, although there are some mines that blast in these conditions. Reactive ground is another circumstance in which stemming holes is thought to be undesirable. As the exothermic reaction perpetuates in the explosive column the explosives heat up, much like in hot holes. The primary difference being that reactive ground will not show any signs of heating prior to the explosive being charged into the hole.

Slightly more formal literature exists for the management of reactive ground than that for hot holes. Most of the publications tend to deal with specialized explosives that inhibit the reaction between the ammonium nitrate and the sulphides from the rock, such as the work of Djerdjev et al. (2018). Reactive ground is particularly dangerous as the explosives heat rapidly in the intermediate stage where an increase of more than $100^{\circ} \mathrm{C}$ can occur in a few minutes (Botha, 2014). Botha (2014) states that even without the detonator and booster in the hole, the explosives can detonate. However, should the conditions not be ideal the explosives will deflagrate. Botha (2014) mentions the following methods of controlling self-detonation in reactive ground:
> Temperature logging
> Load and shoot
> Specialized stemming material
- Physical separation
> Inhibited explosives
> Integrated risk management.

Only limited information concerning stemming reactive ground was found in the literature, although two recommendations were observed. The first being that should stemming be carried out in reactive ground it should be done with an inert material. A specific concern was raised regarding the use of drill chippings, which may contain sulphides that could react with the explosives (Australian Explosives Industry and Safety Group, 2007; Botha, 2014). The second observation is that stemming in reactive ground should be done as quickly as possible. Botha (2014) found that stemming a 280-hole blast at Goedgevonden mine took 3.2 days, resulting in excessive sleep times for the explosives. As with hot holes, time is of the essence for safe blasting in reactive ground. The longer the explosives remain in contact with reactive ground, the higher the risk of a reaction between the ammonium nitrate and sulphides in the hole. Botha (2014) concluded that if the environmental factors allow, confirmed reactive ground blasts should be initiated without stemming the holes to reduce the preparation time'. Rorke (2010) similarly stated, 'whenever the environmental considerations allow an increase in flyrock and air-blast the holes may need to be left unstemmed'. This is because unstemmed holes are less confined and the hole is likely to deflagrate rather than detonate if the temperature exceeds $300^{\circ} \mathrm{C}$ (Rorke, 2011).

There is limited literature pertaining to the effect stemming has on the confinement of explosives in reactive ground. Based on the available information, the decision whether to stem holes in reactive ground depends on the tolerability of flyrock and air-blast for a given blast. Additionally, should stemming be necessary to limit flyrock and air-blast in a reactive ground blast, an inert material that can be quickly loaded into the holes should be used.

\section{Stemming effectiveness metric}

Before the recommendations for stemming lengths and materials can be discussed it is important to note that there is currently no universal metric for evaluating the effectiveness of stemming. Laboratory testing on stemming typically involves the measurement of pressure differences or explosive performance variables. The problem with laboratory testing is that test charge diameters are typically too small and the detonator takes up too much of the charge. Most modern investigations on stemming performance are done through field experiments. High-speed photography and post-blast metrics such as fragmentation are used to evaluate the stemming performance or impact that stemming had on the blast outcomes. Unfortunately, field testing on stemming performance requires an accurate benchmark for comparison. Many studies found in the literature derive relationships on stemming effectiveness from as little as one blast.

Figure 5 shows the metrics used in the literature to evaluate stemming performance. Stemming ejection velocity is commonly used as a metric for stemming effectiveness. However, reduced stemming ejection velocity often goes hand in hand with poor blast performance (Eloranta, 1994). An effective test for stemming should as far as practically possible include elements of both the laboratory and field metrics over a wide data-set in order to accurately measure the effectiveness of a stemming material. Additionally, all other blasting parameters should remain as constant as possible to reduce the influence of external variables on the results.

\section{Stemming material recommendations}

The choice of stemming material plays a significant role in the effectiveness of the stemming. The use of appropriate stemming material is said to reduce the required length of stemming by $40 \%$ (Konya and Davis, 1978). A reduction in stemming length means that more explosives could be added to the shot-hole if neccessary. Additionally, a shorter stemming length results in better explosive energy distribution in the shot-hole. This will assist with fragmentation, and specifically the fragmentation of the collar region of the shot-hole.

The choice of stemming material will likely be driven by availability and cost. As a result, the use of drill chippings is 


\title{
Stemming and best practice in the mining industry: A literature review
}

common practice, yet it is one of the most inefficient forms of stemming (Konya amd Konya, 2018). The use of drill chippings as stemming material will likely require longer stemming lengths to achieve an adequate level of retention. In order to determine what stemming material is best, recommendations in the literature were compiled in Figure 6. Crushed aggregate of uniform particle size is the most common stemming recommendation. Although only a limited number of studies has been done to validate its effectiveness as a stemming material, it has the most quantitative literature substantiating its use.

No studies could be found where stemming plugs are benchmarked against a crushed aggregate. However, there is sufficient evidence validating the enhancement of nonideal stemming materials such as drill chippings using stemming plugs. (Konya and Konya, 2018).

\section{Stemming length recommendations}

There is no optimal length of stemming that provides the ideal blasting outcome. The determination of stemming length is based on a set of rules of thumb that do not constitute a scientific analysis of the estimation (Sazid, 2014). Stemming length recommendations have largely remained the same since the work of Sir John Fox Burgoyne (1895), who recommended that onethird of the blast-hole should be stemmed.

To date, a stemming length estimation of $0.7 \times$ burden is common practice. Konya and Walter (1991) attempted to trace the origin of the empirically obtained $0.7 \times$ burden rule and found it to be a standardized blasting parameter dating back to 1903 , when blasting powder was still used. The recommendations for stemming length found in the literature are compiled in Figure 7. It was found that stemming relationships to burden are most effective for larger hole diameters, and stemming lengths based on the hole diameter for smaller hole diameters. For large boreholes, stemming $0.7 \times$ burden is best when an effective stemming material is used, such as crushed aggregate, and 1.0 $\times$ burden for stemming material such as drill chippings. For smaller hole diameters a range of $20-30 \times \emptyset$ is best. In order to determine which end of the range the following variables should be considered (Tobin, 2013):

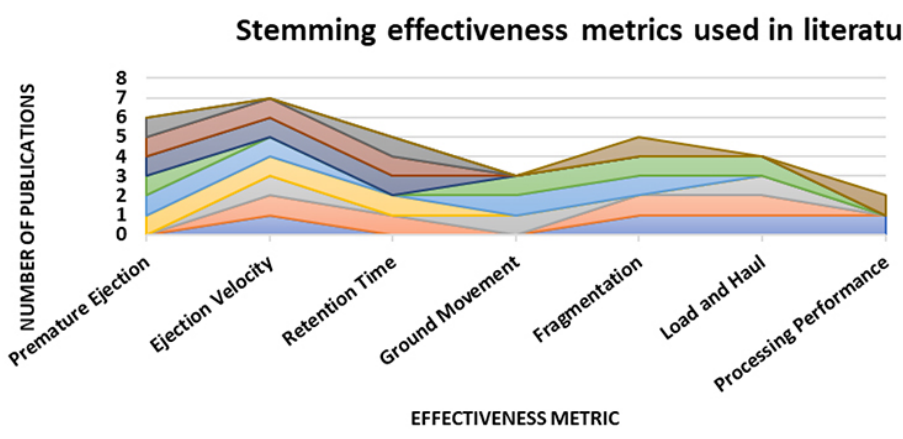

\author{
$\square$ Kojovic (2005) \\ 口Otuonye (1981) \\ $\square$ Kopp (1987) \\ 口Dobrilovic (2005) \\ $\square$ Sharma and Rai (2015) \\ $\square$ Armstrong L (1994) \\ $\square$ Karakus et al (2003) \\ $\square$ Goswami (2000) \\ $\square$ Sazid (2014) \\ 口Eloranta (1994)
}

Figure 5-Stemming effectiveness metrics found in the literature
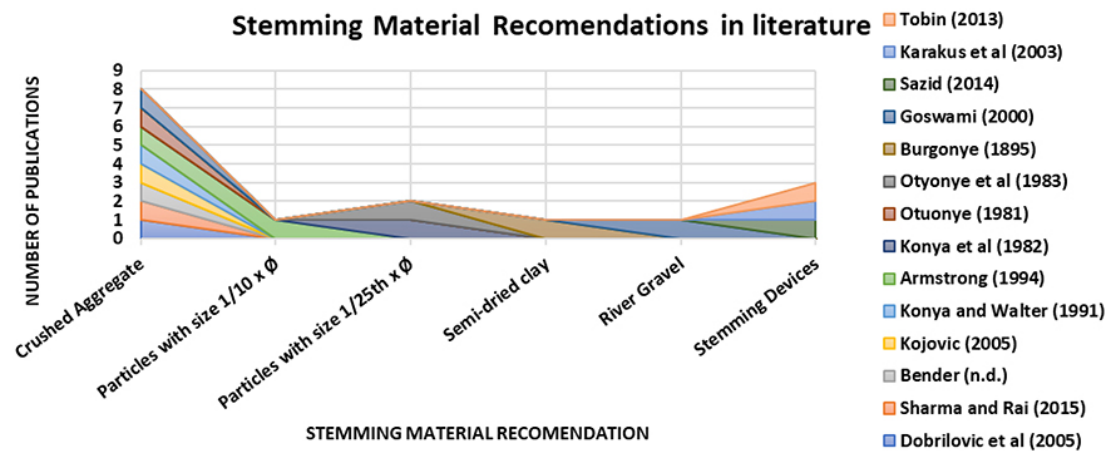

Figure 6-Stemming material recommendations in the literature
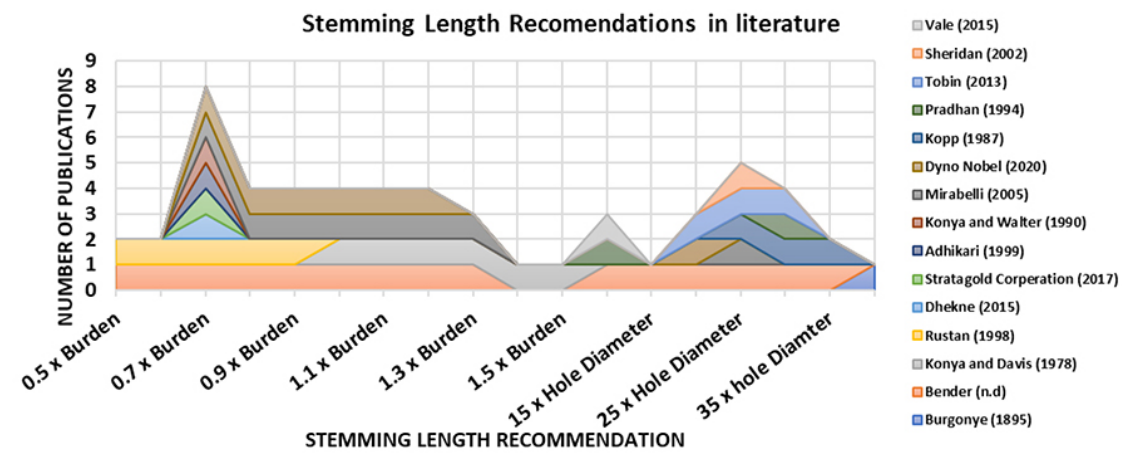

Figure 7-Stemming legnth recommendations in literature 


\section{Stemming and best practice in the mining industry: A literature review}

$>$ Rock strength

$>$ Charge energy

> Burden size and strength

> Water in the blast-hole

> Portion of loose material such as drill chippings in the stemming material.

\section{Regulatory requirements for stemming.}

The South African regulations pertaining to stemming are among the best that can be found globally. While no specific mention of stemming lengths or materials were found in the Canadian and Indian explosive regulations, the South African, Australian, and American regulations do contain such information. The current South African regulations take a consultative and risk-adjusted approach to the selection of stemming material and quantity. The considerations mentioned in the risk-adjusted approach are salient and comprehensive, making the South African regulations pertaining to stemming a world leader.

\section{Conclusion}

This research aimed to determine the necessity of stemming through a literature review. Based on the findings, it is recommended that shot-holes be always stemmed. The control of adverse blasting phenomena such as flyrock, air-blast, and blasting fumes, as well as the significant explosive performance benefits derived from the use of adequate stemming, necessitate its use.

Without an appropriate metric by which to evaluate the effectiveness of stemming it is difficult to determine what quantity and type of stemming material is best. The literature generally recommends the use of a crushed aggregate and a stemming length of 20-30 $\times \emptyset$ for small hole diameters and a length of $0.7 \times$ burden for larger hole diameters.

There are scientific reasons not to stem holes in the case of pre-split, hot hole, and reactive ground blasting. However, there is limited quantitative information in the public domain to substantiate this. Additionally, leaving holes unstemmed results in increased flyrock and air-blast generation, which is undesirable. A risk-adjusted trade-off is therefore required to balance the risks associated with firing unstemmed holes versus stemmed holes in these circumstances.

The South African explosive regulations relating to stemming are world-leading. The risk-adjusted approach is the most flexible regulatory approach found in this study. The correct use of stemming offers significant improvements to blast performance and safety. Stemming should therefore always be used unless the risk of using stemming outweight the benefits.

\section{References}

ADHIKARI, G.R. 1999. Studies on Flyrock at Limestone Quarries. Rock Mechanics and Rock Engineering, vol. 32, no. 4. pp. 29-1301.

Armaghani, D.J. et al., 2015. Application of two intelligent systems in predicting environmental impacts of quarry blasting. Saudi Society for Geosciences, vol. 8, pp. 9647-9665.

Armstrong, L.W. 1994. The quality of Stemming in Assessing Blazsting Efficiency, New South Wales: The University of New South Wales.

Australian Explosives Industry and SAfety Group. 2007. Code of Practice-Elevated Temperature and Reactive Ground, s.l.: AEISG.

BAJPAYEE, T.S. et al., 2001. Fatal accidents due to flyrock and lack of blast area security and working practices in mining, Pennsylvania: National Institute for Occupational Safety and Health Pittsburgh.
Bajpayee, T.S., Verakis, H.C., and LobB, T.E. 2002. An Analysis and Prevention of Flyrock Accidents in Surface Blasting Operations, s.l.: s.n.

Bansah, K.J., Аrкo-Gyimah, K., KansaKe, B.A, and Dumakor-Dupey, N.K. 2016. Mitigating Blast Vibration Impact. UMat Biennial International Mining and Mineral Conference, vol. 4, pp. 30-36.

BELLAIRS, P. and SEN, G.,2004. Blasting safely and efficently in reactive ground and efficently in reactive ground and or hot gorund or in sulphide dust explosion generating rock, s.l.: Mines Angnic Egal Itee.

BENDER, W.L., n.d. Back to Basics - The fundamentals of blast design. Golden West, International Society of Explosive Engineers.

BHP Billiton. 2008. Guidelines to hot drilling and blasting. [Online] Available at: https://www.slideserve.com/santo/guidelines-to-hot-hole-drilling-and-blasting [Accessed 18 January 2020].

BME. 2018. Surface mining blasting guide. 13 ed. s.l.:Omina Group (Pty) Ltd.

Вотна, G.L. 2014. Management of Reactive Ground at the Goedgevonden Opencast Coal Mine in the Witbank Coalfields of South Africa, Johannesburg: University of Witwatersrand.

Burgonye, S.J.F. 1895. A Treatise on the Blasting and Quarrying of Stone for Building and Other Purposes: With the Constituents and Analyses of Granite, Slate, Limestone, and Sandstone. To which is Added Some Remarks on the Blowing Up of Bridges. London: Crosby Lockwood and Son.

Correa, C.E. and Navarrete, M.F. 2004. Assesment of Stemming Plug Plastic Elements to Improve Blasting Gases Confinement in Escondida. EXPLO, pp. 95-100.

Cunningham, C.V., Zaniewski, T., and Kernahan, N.,2002. Threshold Blasting: The Renaissance of Explosives in narrow reef mining. The Journal of The South African Institute of Mining and Metallurgy, pp. 25-31.

Dally, J.W., Fourney, W.L., and Holloway, D.C. 1975. Influence of Containment of the Bore Hole pressures on Explosive Induced Fracture. International Journal of Rock Mechanics, Mineral Science and Geomechanics, vol. 12, pp. 5-12.

Department of Mineral Resources. 2018. Regulations Relating to Explosives - Mine Health and Safety Act, 1996 (Act No 29 of 1996), Pretoria: Government Gazette.

DHEKNE, P.Y. 2015. Environmental Impacts of Rock Blasting and Their Mitigation. International Journal of Chemical, Environmental \& Biological Sciences, vol. 3, no. 1. pp. 46-50.

Dindarloo, S. R., Askarnejad, N. A., and Ataei, M. 2015. Design of controlled blasting (pre-splitting) in Golegohar iron ore mine, Iran. Institute of Materials, Minerals and Mining Science and Technology, vol. 124, no. 1. pp. 64-68.

DJERDJEv, A.M. et al., 2018. The mechanism of spontaneous detonation of ammonium nitrate in reactive grounds. Journal of Environmental Chemical Engineering, vol. 6. pp. 281-288.

Dobrilovic, M., Ester, Z., and JAnkovic, B. 2005. Measurement in blast hole stem and influence of steming material on blasting quality. The Mining-GeologicalPetroleum Engineering Bullitin, vol. 17. pp. 47-53.

Downs, G. 2012. Flyrock damage outside the blast-exclusion zone. [Online] Available at: https://www.dnrme.qld.gov.au/business/mining/safety-andhealth/alerts-and-bulletins/explosives/flyrock-damage-outside-the-blastexclusion-zone [Accessed 25 October 2020].

Dyno Nobel. 2020. Explosives Engineers' Guide. [Online] Available at: https://www. dynonobel.com/apac/ /media/Files/Dyno/ResourceHub/Brochures/APAC/ Explosives\%20Engineers\%20Guide.pdf [Accessed 02 November 2020].

EAdes, R.Q. and PerRy, K. 2019. Understanding the Connection Between Blasting and Highwall Stability. International Journal of Mining Science and Technology, vol. 29. pp. 99-103.

Elevl, B. and Arpaz, E. 2010. Evaluation of Parameters Affected on the Blast Induced Ground Vibration (BIGV) by Using Relatioin Diagram Method. Acta Montanistica Slovaca, vol. 4. pp. 261-268.

EloRANTA, J. 1994. Stemming Selection for Large-Diamter Blastholes, s.l.: Minntac Mine. 


\section{Stemming and best practice in the mining industry: A literature review}

Etchells, S. ., Sellers, E.J., and Furtney, J. 2013. Understanding the Blast Damage Mechanisms in Slopes Using Observations and Numerical Modelling, Perth: Australian Centre for Geomechanics.

Ghasemi, E., Sari, M., and Ataei, M., 2012. Development of an emperical model for predicting the effects of controlable blasting parameters on flyrock distance in surface mines. International Jouranla of Rock Mechanics \& Mining Sciences, vol. 52. pp. 163-170.

Goswami, T. 2000. Assessment of the Relative Efficiency of Two Stemming Materials. s.l., s.n., pp. 171-182.

GovernMENT OF INDIA. 2006. Notice: Firing of Shots in Fire Areas/ in Vicinity of Hot Strata in Opencast Coal Mine, s.l.: Ministry of Labour \& Employment, Directorate-General of Mines Safety.

ISEE. 2011. Blasters' Handbook. 18th ed. Cleavland, Ohio USA 441392295: Initernational Society of Explosives Engineers.

Just, J.D. 1979. Stemming of Blastholes in Mining Excavations. Australian institute of minerals and metallurgy, pp. 7-15.

KaraKus, D., Onur, A.H., KonaK, G., and Kose, H. 2003. Application of Stemming Plugs and A Case Study in A Limestone Quarry. Turkey, International Mining Congress and Exhibition of Turkey.

Kojovic, T. 2005. Influence of Aggregate Stemming in Blasting on the SAG Mill Performance. Minerals Engineering, vol. 18. pp. 1398-1404.

Konya , C.J. and Davis, J. 1978. The Effects of Stemming Consist on Retention in Blast Holes. s.l., ISEE, pp. 102-112.

Konya, A. and Konya, C.J. 2017. Pit \& QUarry. [Online] Available at: https://www. pitandquarry.com/resolving-explosives-inefficiency/[Accessed 03 May 2020].

Konya, C.J. and Konya, A. 2018. Effect of Hole Stemming Practices on Energy Efficiecy of Comminution. In: K. Awuah-Offei, ed. Energy Efficiency in the Minerals Industry. Cham: Springer, pp. 31-53.

Konya, C.J. and WALTER, E.J. 1991. Rock Blasting and Overbreak Control, Virginia: U. S. Depatment of Transportation.

Lachamp, M., Grannas, S., AND Chavez, R. 2020. Influence of Stemming Length and Initiation Sequence on Rock Movement and Dilution During a Blast, s.l.: EFEE.

Maniero, R.J., Harris, M.L., and Rowland, J.H. 2007. Dangers of Toxic Fumes from Blasting. Nashville, International Society of Explosives Engineers.

McHugh, S. 1983. Crack Extension Caused by Internal Gas Pressure Compared with Extension Caused by Tensile Stress. International Jouranal of Fracture, vol. 21, pp. 163-176.

MiRABELl, L. 2005. Blast Management - National Quarry Academy, s.l.: Quarry Academy 2005.

OTuonye, F.O. 1981. PHD, Effective blasthole stemming, Ohio: The Ohio State University.

Otuonye, F.O., SкіDмоRe, D.R., and Konya, C.J. 1983. Measurements and Predicitons of Borehole Pressure Variations in Model Blasitng Systems. Lulea, Sweden, First International Symposium on Rock Fragmentation by Blasting.

PARDHAN, G.K. 1994. Explosives and Blasting Techniques. Bhubaneswar, India: Mintech.

PEARTon, S. 2014. Evaluatinig the Viability of Pumpable Emulsion Explosives for use in Narrow Reef Mining Operations, Johannesburg: University of Witwatersrand.

РнамотSE, K.M. and NнLеко, A.S. 2019. Determination of optimal fragmentation curves for a surface diamond mine. Journal of the Southern African Institute of Mining and Metallurgy, vol. 119, pp. 613-619.

Radomsky, M. and Kecojevic, V. 2005. Flyrock Phenomena and Area Security in Blasting-Related Accidents. Safety Science, vol. 43. pp. 739-750.

RatclifF, J., Sheehan, E., and Carte, K. 2011. Predictability of Airblast at Surface Coal Mines in West Virginia, West Virginia: Office of Explosives and Blasting (OEB).

Richards, A.B. 2013. Predictive Modelling of Airblast Overpressure. Institute of Materials, Minerals and Mining and the AusIMM, vol. 122, no. 4, pp. 215-220.
Richards, A. B. \& Moore, A. J., 2005. Golden pike cut-back flyrock control and calibration of a predictive model, s.l.: Terrock Consulting Engineers.

RoRкE, A.J. 2011. Blasting Impact Assessment for the proposed New Largo Colliery, s.l.: AJ Rorke.

Rustan, A. 1998. Rock Blasting Terms and Symbols - A Dictionary of Symbols and Terminology in Rock Blasting. 1 ed. London: AA Balkema.

S\&T Projects. 2001. Evaluation of Explosives Performance Through In-The-Hole Detonation Velocity Measurement, Karnataka: National Institute of Rock Mechanics.

SAFF, A.A. 1961. An experimental investigation of the factors influencing the efficent use of explosives in short drill holes, s.l.: University of the Witwatersrand.

SAZID, M. 2014. Investigating the role of effective stemming in engineering blasting operations for open-pit mines, s.l.: Department of Earth Sciences, Indian Institute of technology bombay.

SAzid, M., SAharan, M.R., and Singh, T.N. 2016. Enhancement of the Explosive Energy Utilization with the Application of New Stemming Contrivance. International Journal of Innovative Science and Modern Engineering, vol. 4, no. 2. pp. 2319-6386.

Sharma, P. D. 2010. Charging and Blasting in Hot Strata Condition in Opencast Coal Mines Most Crucial aspect is implementaion of Effective Safety Management, s.l.: s.n.

Sharma, S.K. and RAI, P. 2015. Investigation of Crushed Aggregate as Stemming Material in Bench Blasting: A Case Study. Geotech Geol Eng, vol. 33. pp. 1449-1463.

SHERIDAN, R.A. 2002. Explosives Information Bulletin - Precautions Agaisnt Flyrock, Queensland: Explosives Inspectorate - Safety and Health Administration.

Singh, P.K., Klemenz, M., and Niemaan-Delius, C. 2005. Air Overpressure. [Online] Available at: https://www.agg-net.com/resources/articles/drilling-blasting/airoverpressure [Accessed 26 October 2020].

SNelling, W.O. and HaLl, C. 1912. The effect of stemming on the efficiency of explosives, Washington: United States Government Printing Office.

Standards Australia. 2006. Explosives-Storage and use, Sydney: Standards Austalia.

StrataGold Corperation. 2017. Eagle Gold Project, Explosives Management Plan, s.l.: StrataGold Corperation.

ToBin, G. 2013. The Importance of Energy Containment to the Blsat Outcome \& Justification for use of Stemming Plugs in Over Burden Removal, Australia: Oresome Products Pty Ltd.

Tose, S.S.J. 2006. A Review of the Design Criteria and Practical Aspects of Developing a Successful Pre-Split. The South African Institute of Mining and Metallurgy, pp. 525-546.

Trivedi, R., Singh, T.N., and GuPTA, N. 2015. Prediction of Blast-Induced Flyrock in Opencast Mines Using ANN and ANFIS. Geotech Geol Eng, vol. 33. pp. $875-891$.

U.S. Department of THE InTERIoR, n.d. Office of Surface Mining Reclamation and Enforcement. [Online] Available at: https://www.osmre.gov/resources/blasting/ docs/WYBlasterCertModules/8AdverseEffectsBlasting.pdf [Accessed 1701 2020].

UnIVERSITY of Pretoria. 2016. UP Research Summary, s.l.: Univeristy of Pretoria.

VALE, 2015. Blast Managment Plan, Singleton, Hunter Valley: Integra Coal Operations.

VALE. 2019. Hot Hole Charging Procedure, s.l.: Vale.

VAN DER WALt, J. and SPITERI, W. 2020. A critical analysis of recent research into the prediction of flyrock and related issues resulting from surface blasting activites. SAIMM. pp. 701-714.

Zhang, Z.-X., De-Feng , H., Guo, Z., and He, Z. 2020. Labratory experiment of stemming impact on rock fragmentation by a high explosive. Tunnelling and Underground Space Technology, vol. 97, no. 1. pp. 1-10.

ZHANG, Z.X.,2016. Stemming and Charge Length. In: M. K. Leme, ed. Rock Fracture and Blasting. s.l.:Joe Hayton, pp. 271-281. 